\title{
Does bullying cause emotional problems? A prospective study of young teenagers
}

\author{
Lyndal Bond, John B Carlin, Lyndal Thomas, Kerryn Rubin, George Patton
}

\begin{abstract}
Centre for
Adolescent Health,

Royal Children's

Hospital, Parkville

3052, Victoria,

Australia

Lyndal Bond

head, research unit

Kerryn Rubin

medical student

George Patton

director

Clinical

Epidemiology and

Biostatistics Unit

Murdoch Children's

Research Institute

and University of

Melbourne

Department of

Paediatrics, Royal

Children's Hospital

John B Carlin

director

Lyndal Thomas

PhD scholar

Correspondence to:

L Bond

bond@cryptic.rch.

unimelb.edu.au
\end{abstract}

BMJ 2001;323:480-4

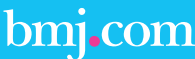

Questionnaires used in the study are on the BMJ's website

\begin{abstract}
Objectives To establish the relation between recurrent peer victimisation and onset of self reported symptoms of anxiety or depression in the early teen years.

Design Cohort study over two years.

Setting Secondary schools in Victoria, Australia. Participants 2680 students surveyed twice in year 8 (aged 13 years) and once in year 9 .

Main outcome measures Self reported symptoms of anxiety or depression were assessed by using the computerised version of the revised clinical interview schedule. Incident cases were students scoring $\geqslant 12$ in year 9 but not previously. Prior victimisation was defined as having been bullied at either or both survey times in year 8 .

Results Prevalence of victimisation at the second survey point in year 8 was $51 \%$ (95\% confidence interval $49 \%$ to $54 \%$ ), and prevalence of self reported symptoms of anxiety or depression was $18 \%$ (16\% to $20 \%$ ). The incidence of self reported symptoms of anxiety or depression in year $9(7 \%)$ was significantly associated with victimisation reported either once (odds ratio $1.94,1.1$ to 3.3$)$ or twice $(2.30,1.2$ to 4.3$)$ in year 8 . After adjustment for availability of social relations and for sociodemographic factors, recurrent victimisation remained predictive of self reported symptoms of anxiety or depression for girls (2.60, 1.2 to 5.5) but not for boys (1.36, 0.6 to 3.0). Newly reported victimisation in year 9 was not significantly associated with prior self report of symptoms of anxiety or depression (1.48, 0.4 to 6.0$)$.

Conclusion A history of victimisation and poor social relationships predicts the onset of emotional problems in adolescents. Previous recurrent emotional problems are not significantly related to future victimisation. These findings have implications for how seriously the occurrence of victimisation is treated and for the focus of interventions aimed at addressing mental health issues in adolescents.
\end{abstract}

\section{Introduction}

Bullying occurs in all schools, but its relevance to health and wellbeing is uncertain. ${ }^{1-3}$ On the one hand it can be considered a common and normal developmental experience; alternatively, it can be considered an important cause of stress and of physical and emotional problems. ${ }^{4-6}$ A meta-analysis of studies investigating the relation between victimisation and psychosocial maladjustment found a stronger association with measures of depression than with anxiety, loneliness, or general self esteem.

Unfortunately, the cross sectional design of most studies precludes inferences about causality. The few available prospective studies have generally focused on primary school children before the early increase in depression in adolescence, ${ }^{7}$ with the principal out- comes being school maladjustment, loneliness, and depression. ${ }^{8-10}$ One small longitudinal study of adolescents found that high levels of victimisation predicted poor physical health for boys and girls and poor mental health for girls. ${ }^{11}$ Olweus found that boys victimised between the ages of 12 and 16 had increased levels of depression as young adults; however, no adjustment was made for previous mental health states in this study. ${ }^{5}$

We carried out a prospective study of secondary school students. The data derive from three waves of data collected from students involved in a randomised controlled trial of a school based intervention to promote the emotional wellbeing of young people. ${ }^{12}$ Intervention effects in the trial are not the main focus of this paper. Data were collected at the beginning and end of year 8 (second year of secondary school, mean age 13 years) and 12 months later (end of year 9). Our aim was to use these prospective data to examine the relation between a history of victimisation (in year 8) and the incidence of self reported symptoms of anxiety or depression in year 9 .

\section{Methods}

A cluster randomised controlled design was used for the allocation of education districts to intervention or control status. In metropolitan Melbourne, 12 districts were sampled with a probability proportional to the number of secondary schools (including government, independent, and Catholic schools) and were randomly allocated to intervention or control status. We used simple random sampling to select 12 schools from the "intervention" districts and 12 from the "control" districts. Six country schools were randomly drawn from two regional districts. Twenty six (12 intervention and 14 control) schools agreed to participate.

Students completed a self administered questionnaire at school using laptop computers provided by the research team. Questionnaires took approximately 40 minutes to complete. Absent students were surveyed at school at a later date or by telephone.

Ethics approval was granted by the Royal Children's Hospital ethics in human research committee, the Victorian Department of Education, Employment and Training, and the Catholic Education Office. Student participation was voluntary, with written parental consent required.

\section{Victimisation}

Participants were classified as victimised if they answered yes to items addressing four types of recent victimisation: being teased, having rumours spread about them, being deliberately excluded, or experiencing physical threats or violence. Respondents were classified on the basis of self report in year 8 as having experienced recurrent victimisation if they reported having been bullied at both times in year 8 (waves 1 and 2). 
Table 1 Associations between social and sociodemographic measures and victimisation and self reported symptoms of anxiety or depression at year 8 (wave 1)

\begin{tabular}{|c|c|c|c|c|c|c|c|}
\hline & \multirow[b]{2}{*}{$\begin{array}{c}\text { Total } \\
(\mathrm{n}=2559)\end{array}$} & \multicolumn{3}{|c|}{ Victimised $(\mathrm{n}=986)$} & \multicolumn{3}{|c|}{ Symptoms of depression* $(n=356)$} \\
\hline & & № (\%) & $\begin{array}{l}\text { Odds ratio } \\
\text { (95\% Cl) }\end{array}$ & $P$ value & No (\%) & $\begin{array}{l}\text { Odds ratio } \\
(95 \% \mathrm{Cl})\end{array}$ & $P$ value \\
\hline \multicolumn{8}{|l|}{ Sex: } \\
\hline Male & 1195 & $600(50.2)$ & 1.00 & & $138(11.5)$ & 1.00 & \\
\hline Female & 1364 & $664(48.7)$ & $0.94(0.8$ to 1.1$)$ & 0.440 & $272(19.9)$ & $1.91(1.4$ to 2.5$)$ & $<0.001$ \\
\hline \multicolumn{8}{|l|}{ Family structure: } \\
\hline Intact family & 2075 & $986(47.5)$ & 1.00 & & $307(14.8)$ & 1.00 & \\
\hline Separated, divorced, other & 481 & $278(57.8)$ & $1.50(1.2$ to 1.9$)$ & 0.003 & $103(21.4)$ & 1.57 (1.2 to 2.0$)$ & 0.001 \\
\hline \multicolumn{8}{|l|}{ Language spoken at home: } \\
\hline English only & 1955 & $979(50.1)$ & 1.00 & & $302(15.4)$ & 1.00 & \\
\hline Other language (including English and other) & 600 & $285(47.5)$ & $0.90(0.7$ to 1.1$)$ & 0.356 & $108(18.0)$ & $1.20(0.9$ to 1.6$)$ & 0.173 \\
\hline \multicolumn{8}{|l|}{ Availability of attachments: } \\
\hline Good & 2008 & $1008(50.2)$ & 1.00 & & $288(14.3)$ & 1.00 & \\
\hline Poor & 224 & $134(59.8)$ & $1.48(1.0$ to 2.2$)$ & 0.044 & $59(26.3)$ & 2.14 (1.4 to 3.1$)$ & $(0.0)$ \\
\hline Absent or very poor & 157 & $112(71.3)$ & $2.47(1.5$ to 4.0$)$ & 0.001 & $60(38.2)$ & $3.69(2.8$ to 4.9$)$ & $<0.001$ \\
\hline \multicolumn{8}{|l|}{ Arguments with others: } \\
\hline No arguments & 1403 & $613(43.7)$ & 1.00 & & $129(9.2)$ & 1.00 & \\
\hline Arguments with one other & 794 & $489(61.6)$ & 2.07 (1.8 to 2.4$)$ & $<0.001$ & $187(23.6)$ & $3.04(2.5$ to 3.7$)$ & $<0.001$ \\
\hline Arguments with two or more others & 207 & $161(77.8)$ & 4.51 (3.0 to 6.8$)$ & $<0.001$ & $93(44.9)$ & 8.06 (5.3 to 12.2$)$ & $<0.001$ \\
\hline \multicolumn{8}{|l|}{ Victimised: } \\
\hline Not bullied & 1295 & & & & $93(7.2)$ & 1.00 & \\
\hline Bullied & 1264 & & & & $317(25.1)$ & 4.33 (3.3 to 5.7$)$ & $<0.001$ \\
\hline \multicolumn{8}{|l|}{ Severity of victimisation: } \\
\hline Not bullied & 1141 & & & & $92(8.1)$ & 1.00 & \\
\hline Bullied, but not frequently and not upset & 693 & & & & $117(16.9)$ & 2.32 (1.7 to 3.2$)$ & $<0.001$ \\
\hline Bullied, either frequently or upset & 381 & & & & $98(25.7)$ & 3.95 (2.9 to 5.4$)$ & $<0.001$ \\
\hline Bullied, frequently and upset & 190 & & & & $102(53.7)$ & 13.22 (8.8 to 19.8 ) & $<0.001$ \\
\hline
\end{tabular}

${ }^{\star}$ Score $\geqslant 12$ on revised clinical interview schedule.

\section{Mental health status}

Mental health status was evaluated with a computerised version of the revised clinical interview schedule, a structured psychiatric interview for non-clinical populations. ${ }^{13} 14$ The schedule comprises 14 subscales. It has been used as a criterion measure for the definition of caseness in teenagers ${ }^{15}$ and it has an ease of reading suitable for young adolescents (Fleisch reading ease 78.5). A score of $\geqslant 12$ provides a criterion measure of minor psychiatric morbidity at which a general practitioner might be concerned. ${ }^{14}$

An incident case with self reported symptoms of anxiety or depression was defined as someone who scored $<12$ on the interview schedule at both times in year 8 (waves 1 and 2) and scored $\geqslant 12$ at year 9 . Participants scoring $\geqslant 12$ at both times in year 8 were classified as having "recurrent" self reported symptoms of anxiety or depression.

\section{Social relations}

Indicators of perceived availability of attachments and conflictual relationships were adapted from the interview schedule for social interaction. ${ }^{16}$ Perceived availability of attachments was assessed in terms of "having someone to talk to or depend on when angry or upset" or "when having a tough time" and "having someone who knows one well and can be trusted with private feelings and thoughts." Participants were categorised as having good availability of attachments at both times in year 8 , poor availability reported at either time in year 8 , or absent or very poor availability at both times in year 8 . The social attachment scale has an internal consistency of 0.69 .

For conflictual relationships, participants were categorised as reporting no arguments at baseline, arguments with one person at either time in year 8, or arguments with two or more people at either time.

\section{Family measures}

Family measures were family structure (intact family, separated/divorced parents, or other circumstances) and language spoken at home as a marker of ethnicity.

\section{Method of analysis}

Results are based on participants for whom information about victimisation and mental health status was available for all waves (2365) or who had missing data at either wave 1 or wave 2 only (194). For these 194 students a conservative assumption was made of no bullying and no symptoms of depression for the wave for which the data were missing.

Simple bivariate associations were estimated by using odds ratios and tested with the $\chi^{2}$ test. To account for the cluster sampling, robust "sandwich" estimates of

Table 2 Associations between incident self reported symptoms of anxiety or depression in year $9(n=1901)$ and history of victimisation and between first reported victimisation in year $9(n=853)$ and history of self reported symptoms of anxiety or depression, adjusted for sex

\begin{tabular}{|c|c|c|c|c|c|}
\hline & $\begin{array}{c}\text { Total } \\
\text { No }\end{array}$ & $\begin{array}{l}\text { Symptoms of } \\
\text { depression* } \\
\text { (No (\%)) }\end{array}$ & $\begin{array}{c}\text { Bullied } \\
\text { (No (\%)) }\end{array}$ & $\begin{array}{l}\text { Odds ratio } \\
(95 \% \mathrm{Cl})\end{array}$ & $P$ value \\
\hline \multicolumn{6}{|l|}{ Bullied in year 8: } \\
\hline At neither time & 763 & $35(4.6)$ & & 1 & \\
\hline At one time & 645 & $54(8.4)$ & & 1.94 (1.1 to 3.3$)$ & 0.015 \\
\hline At both times & 493 & $46(9.3)$ & & 2.30 (1.2 to 4.3$)$ & 0.013 \\
\hline \multicolumn{6}{|c|}{ Symptoms of depression in year $8^{\star}$ : } \\
\hline At neither time & 763 & & $141(18.5)$ & 1 & \\
\hline At one time & 70 & & $15(21.4)$ & 1.21 (0.7 to 2.2$)$ & 0.510 \\
\hline At both times & 20 & & $5(25)$ & $1.48(0.4$ to 5.6$)$ & 0.691 \\
\hline
\end{tabular}

${ }^{*}$ Score $\geqslant 12$ on revised clinical interview schedule. 
Table 3 Multivariate logistic regression for incident self reported symptoms of anxiety or depression at year 9. Values are numbers (percentages) unless otherwise stated

\begin{tabular}{|c|c|c|c|c|}
\hline & $\begin{array}{l}\text { Incident symptoms of } \\
\text { anxiety or depression } \\
\text { at year } 9(n=116)^{\star}\end{array}$ & $\begin{array}{c}\text { Total } \\
(n=1746)^{\star}\end{array}$ & $\begin{array}{l}\text { Adjusted odds } \\
\text { ratio† (95\% Cl) }\end{array}$ & $\begin{array}{c}\mathbf{P} \\
\text { value }\end{array}$ \\
\hline \multicolumn{5}{|l|}{ Victimised at baseline: } \\
\hline Not bullied in year 8 & $28(24.1)$ & $680(38.9)$ & 1.00 & \\
\hline Bullied at one time in year 8 & $42(36.2)$ & $575(32.9)$ & 1.49 (0.88 to 2.54$)$ & 0.130 \\
\hline Bullied at both times in year 8 & $46(39.7)$ & $491(28.1)$ & $2.03(1.14$ to 3.64$)$ & 0.019 \\
\hline \multicolumn{5}{|l|}{ Availability of attachments at baseline: } \\
\hline Available at both times in year 8 & $96(82.8)$ & $1501(86.0)$ & 1.00 & \\
\hline Available at one time in year 8 & $17(14.7)$ & $217(12.4)$ & $1.25(0.53$ to 2.96$)$ & 0.594 \\
\hline No available attachments in year 8 & $3(2.6)$ & $25(1.4)$ & $1.97(0.43$ to 9.05$)$ & 0.366 \\
\hline \multicolumn{5}{|l|}{ Arguments with others at baseline: } \\
\hline None at baseline & $31(26.7)$ & $837(47.9)$ & 1 & \\
\hline With one other at either time & $67(57.8)$ & $798(45.7)$ & 1.86 (1.05 to 3.30$)$ & 0.036 \\
\hline $\begin{array}{l}\text { With two or more others at } \\
\text { either time }\end{array}$ & $18(15.5)$ & $104(6.0)$ & $4.25(1.82$ to 9.94$)$ & 0.002 \\
\hline \multicolumn{5}{|l|}{ Sex: } \\
\hline Male & $40(34.5)$ & $868(49.7)$ & & \\
\hline Female & $76(65.5)$ & $878(50.3)$ & 1.86 (1.02 to 3.40$)$ & 0.044 \\
\hline \multicolumn{5}{|l|}{ Family structure: } \\
\hline Intact family & $86(74.1)$ & $1422(81.4)$ & 1.00 & \\
\hline Separated, divorced, other & $30(25.9)$ & $324(18.6)$ & $1.47(0.9$ to 2.4$)$ & 0.116 \\
\hline
\end{tabular}

*Numbers reduced owing to missing data for social relationship variables.

†Adjusted also for group.

Table 4 Multivariate logistic regression for incident self reported symptoms of anxiety or depression for boys and girls in year 9

\begin{tabular}{|c|c|c|c|c|}
\hline & \multicolumn{2}{|c|}{ Girls $\left(76 / 857^{*}\right)$} & \multicolumn{2}{|c|}{ Boys $\left(40 / 853^{*}\right)$} \\
\hline & $\begin{array}{l}\text { Adjusted odds } \\
\text { ratio† }(95 \% \mathrm{Cl})\end{array}$ & $P$ value & $\begin{array}{l}\text { Adjusted odds } \\
\text { ratio† }(95 \% \mathrm{CI})\end{array}$ & $P$ value \\
\hline \multicolumn{5}{|l|}{ Victimised at baseline: } \\
\hline Not bullied in year 8 & 1.00 & & 1.00 & \\
\hline Bullied at one time in year 8 & $1.90(0.8$ to 4.4$)$ & 0.123 & $0.93(0.4$ to 2.2$)$ & 0.863 \\
\hline Bullied at both times in year 8 & 2.60 (1.2 to 5.5$)$ & 0.015 & $1.36(0.6$ to 3.0$)$ & 0.414 \\
\hline \multicolumn{5}{|l|}{ Availability of attachments at baseline: } \\
\hline Available at both times in year 8 & 1.00 & & 1.00 & \\
\hline Available at one time in year 8 & $0.93(0.3$ to 2.8$)$ & 0.892 & $1.57(0.4$ to 6.7$)$ & 0.649 \\
\hline No available attachments in year 8 & $5.66(1.2$ to 26.6$)$ & 0.030 & $0.90(0.10$ to 7.9$)$ & 0.927 \\
\hline \multicolumn{5}{|l|}{ Arguments with others at baseline: } \\
\hline None at baseline & 1 & & 1 & \\
\hline With one other at either time & 2.27 (1.3 to 4.2$)$ & 0.010 & 1.45 (0.6 to 3.5$)$ & 0.388 \\
\hline With two or more others at either time & $5.02(1.6$ to 15.4$)$ & 0.007 & $3.40(0.9$ to 13.6$)$ & 0.075 \\
\hline \multicolumn{5}{|l|}{ Family structure: } \\
\hline Intact family & 1.00 & & 1.00 & \\
\hline Separated, divorced, other & 1.50 (0.9 to 2.6) & 0.133 & $1.31(0.5$ to 3.6$)$ & 0.571 \\
\hline
\end{tabular}

*Numbers reduced owing to missing data for social relationship variables.

†Adjusted also for group-intervention or control.

standard errors were calculated by using survey estimation methods (Stata Statistical Software version 6.0, Stata Corporation, College Station, TX). To model potential confounding effects, multiple logistic regression was used, again with adjustment for clustering using survey estimation methods. Estimates of population attributable fraction adjusted for confounders were made by using logistic regression models with appropriately adjusted $95 \%$ confidence intervals. ${ }^{17}$

\section{Results}

Of the sample of 3623 students, $2860 \quad(79 \%)$ participated in at least one wave of data collection and $2559(71 \%)$ provided data for this analysis. Small but significant differences were found in some sociodemographic factors for the $222(8 \%)$ with missing data at wave 3 , with higher proportions of boys and of students with non-intact families and families of non-English speaking background than among students without missing data.

The prevalence of victimisation at each of the three survey periods was 49\% (95\% confidence interval 48\% to $53 \%), 51 \%(49 \%$ to $54 \%$ ), and $42 \%$ (39\% to $45 \%$ ). Eight hundred and fifty seven (33\%) respondents were defined as having experienced recurrent victimisation, $853(33 \%)$ reported being bullied at one time point, and $849(33 \%)$ reported no victimisation at either time point in year $8 ; 544(63 \%)$ of those students who were victimised recurrently in year 8 reported being victimised in year 9 .

The prevalence of self reported symptoms of anxiety or depression at each of the three survey points was $16 \%(15 \%$ to $18 \%), 18 \%(16 \%$ to $20 \%)$, and $15 \%$ $(13 \%$ to $16 \%)$. In all, 1901 (74\%) of participants were classified as having no symptoms of anxiety or depression at either wave 1 or wave 2 (clinical interview schedule score $<12$ at both times), 438 $(17 \%)$ scored $\geqslant 12$ on one occasion, and $221(9 \%)$ scored $\geqslant 12$ on both occasions. Of the 1901 who scored $<12$ on the schedule in year $8,136(7 \%)$ scored $\geqslant 12$ in year $9 ; 134(61 \%)$ of those with recurrent self reported symptoms of depression in year 8 reported symptoms in year 9 .

Simple bivariate analyses found significant associations between victimisation, mental health status, and measures of social relationships (table 1).

The association between incident self reported symptoms of anxiety or depression in year 9 and a history of victimisation in year 8 and the impact of mental health status on the incidence of victimisation, with adjustment for sex, are shown in table 2. Any occurrence of victimisation was significantly associated with the incidence of self reported symptoms of anxiety or depression. After adjustment for social relationships and sociodemographic factors, recurrent victimisation remained significantly associated with incident self reported symptoms of anxiety or depression, as did arguments with others, and sex (table 3).

The attributable fraction of students with incident self reported symptoms of anxiety or depression for those exposed to victimisation was 0.50 (0.24 to 0.67$)$. Adjusted for confounders, the population attributable fraction was 0.30 (0.04 to 0.49$)$. The attributable fraction of students experiencing victimisation for the first time in year 9 who had reported symptoms of anxiety or depression previously was 0.21 ( -0.20 to 0.49 ). Adjusted for confounders, the population attributable fraction was 0.003 ( -0.05 to 0.05$)$.

Table 4 shows the adjusted odds ratios for boys and girls, given the known sex differences in self reported symptoms of anxiety or depression and social relationships. For boys, none of the variables remains independently significant in the model. Owing to the small number of incident cases who were boys, this analysis was repeated including only victimisation and arguments with others. This made no substantial difference to the estimation of odds ratios.

\section{Discussion}

The prevalence of victimisation was high and relatively stable in this cohort. Two thirds of the students who were bullied recurrently in year 8 also reported being 
bullied in year 9 . This study confirmed the strong contemporaneous association between victimisation and self reported symptoms of anxiety or depression previously reported. ${ }^{19}{ }^{18} \mathrm{We}$ also found a strong association with social relationships, which has been less well documented in the adolescent age group. Most importantly, we found that a history of victimisation is a strong predictor of the onset of self reported symptoms of anxiety or depression and remains so after adjustment for other measures of social relations. The contrary hypothesis that having poor emotional health in some way invites victimisation or represents a vicious cycle has not been supported by these data. ${ }^{19-21}$

Affective disorders become common in adolescence, as symptoms of depression and anxiety increase after puberty. ${ }^{72}$ A prevalence of $16 \%$ of self reported symptoms of anxiety or depression in young secondary school students, with sex differences in the prevalence, is therefore consistent with previous findings. ${ }^{722}$

In this study, in up to $30 \%$ of all students with incident symptoms of depression, the symptoms could be attributed to a history of victimisation, after adjustment for other confounders. Although one must bear in mind the limitations in interpreting population attributable fractions, ${ }^{23}$ it remains clear that the impact of victimisation on incident self reported symptoms of anxiety or depression in this population is potentially great.

Furthermore, this effect of bullying on mental health status is clearest for girls. That is, being victimised has a significant impact on the future emotional wellbeing of young adolescent girls independent of their social relations but does not for boys. This finding may be due to a real difference in the boys' response to victimisation or to the small number of boys reporting symptoms of depression. However, the second of these possibilities is a less likely explanation, as a reduction of variables in the model did not substantially alter the finding.

The strengths of this study are its prospective design, the use of two time points to define a baseline of recurrent victimisation and self reported symptoms of anxiety or depression, the inclusion of both overt and covert or relational types of victimisation, and a comprehensive measure of mental health status. It is, however, possible that young people who have not previously reported being victimised in year 8 , at a time when it is relatively common, may be different from their peers in other respects. Although we cannot explicitly examine this possibility with these data, we believe it to be unlikely given the similar relations of the social and family measures to victimisation and emotional health found in the cross sectional data and in previous studies.

The data were collected as part of the assessment of the effect of a school based intervention. ${ }^{12}$ The intervention did not contain activities focusing on victimisation, so it is unlikely to have had an impact on the reported associations. Furthermore, all analyses were statistically adjusted for intervention and control status.

This study has found that victimisation raised levels of subsequent self reported symptoms of anxiety or depression regardless of the coexisting levels of social adversity. This suggests that a reduction in victimisation in schools is potentially a useful preventive interven-

\section{What is already known on this topic}

Being bullied is a common experience for many young people

Victimisation is related to depression and, to a lesser extent, anxiety, loneliness, and general self esteem

Debate remains as to whether victimisation precedes the onset of emotional problems or whether young people with emotional problems "invite" victimisation

\section{What this study adds}

A history of victimisation predicts the onset of anxiety or depression, especially in adolescent girls

Previous recurrent emotional problems are not significantly related to future victimisation

Reduction in bullying in schools could have a substantial impact on the emotional wellbeing of young people

tion, especially for girls. Further work is needed to determine if a reduction in victimisation can reduce the onset of symptoms of anxiety and depression in young adolescents, but the indications from this study are that such a reduction could have a substantial impact on the emotional wellbeing of young people.

We acknowledge the valuable contribution made to this study by the staff, young people, and parents in the project schools

Contributors: LB and GP participated in the design and execution of the study, analysis of the data, and writing the paper. JBC and LT participated in analysing and interpreting the data and writing the paper. KR contributed to the analysis of the cross sectional data and development of the bullying severity scale. LB will act as guarantor for the paper.

Funding: The Gatehouse Project is supported by grants from the Queen's Trust for Young Australians, Victorian Health Promotion Foundation, National Health and Medical Research Council, and Department of Human Services.

Competing interests: None declared.

1 Hawker DSJ, Boulton MJ. Twenty years' research on peer victimisation and psychosocial maladjustment: a meta-analytic review of crossand psychosocial maladjustment: a meta-analytic revil studies. J Child Psychol Psychiatry 2000;41:441-55.

2 Dawkins J, Hill P. Bullying: another form of abuse? In: David TJ, ed. Recent advances in pediatrics. Edinburgh: Livingstone, 1995:103-22

3 Salmon G, James A, Smith DM. Bullying in schools: self reported anxiety, depression, and self esteem in secondary school children. $B M J$ 1998;317:924-5.

4 Neary A, Joseph S. Peer victimisation and its relationship to self-concept and depression among schoolgirls. Pers Indiv Diff 1994;16:183-6.

5 Olweus D. Bullying in schools: what we know and what we can do. Oxford: Blackwell, 1993.

6 Rigby K. The relationship between reported health and involvement in bully/victim problems among male and female secondary schoo children.J Health Psychol 1998;3:465-76.

7 Cicchetti D, Toth SL. The development of depression in children and adolescents. Am Psychol 1998;53:221-41.

8 Kochenderfer BJ, Ladd G. Peer victimisation: cause or consequence of school maladjustment? Child Dev 1996;67:1305-17.

9 Boivin M, Hymel S, Bukoski WM. The roles of social withdrawal, peer rejection and victimisation by peers in predicting loneliness and depressed mood in childhood. Dev Psychopathol 1995;7:765-85.

10 Kumpulainen K, Rasanen E, Henttonen I. Children involved in bullying: psychological disturbance and the persistence of the involvement. Child Abuse Negl 1999:23:1253-62.

11 Rigby K. Peer victimisation at school and the health of secondary school students. Br J Educ Psychol 1999;69:95-104.

12 Patton G, Glover S, Bond L, Butler H, Godfrey C, Di Pietro G, et al. The Gatehouse project: a systematic approach to mental health promotion in secondary schools. Aust N Z J Psychiatry 2000;34:586-93.

13 Lewis G, Pelosi AJ, Glover E, Wilkinson G, Stansfeld SA, Williams P, et al. The development of a computerised assessment for minor psychiatric disorder. Psychol Med 1988;18:737-45. 
14 Lewis G, Pelosi AJDG. Measuring psychiatric disorder in the community: a standardised assessment for use by lay interviewers. Psychol Med 1992;22:465-86

15 Monck E, Graham P, Richman N, Dobbs R. Adolescent girls. II. Background factors in anxiety and depressive states. $\mathrm{Br} J$ Psychiatry 1994;165:770-80.

16 Henderson S, Duncan-Jones P, Byrne DG, Scott R. Measuring social relationships. The interview schedule for social interaction. Psychol Med 1980;10:723-34

17 Greenland S, Drescher K. Maximum likelihood estimation of the attributable fraction from logistic models. Biometrics 1993;49:865-72.

18 Craig WM. The relationship among bullying, victimisation, depression, anxiety, and aggression in elementary school children. Pers Indiv Diff 1998;24:123-30
19 Boulton MJ, Underwood K. Bully/victim problems among middle school children. BrJ Educ Psychol 1992;62:73-87.

20 Slee PT, Rigby K. Australian school children's self appraisal of interpersonal relations: the bullying experience. Child Psychiatry Hum Dev 1993;23:273-82.

21 Hodges EVE, Perry DG. Personal and interpersonal antecedents and consequences of victimisation by peers. J Pers Soc Psychol 1999:76:677-85.

22 Patton G, Hibbert M, Carlin JB, Shao Q, Rosier M, Caust J, et al. Menarche and onset of depression and anxiety in Victoria, Australia. J Epidemiol Community Health 1996;50:661-6.

23 Rothman KJ, Greenland S. Modern epidemiology. Philadelphia, PA: Lippincott-Raven, 1998.

(Accepted 21 May 2001)

\title{
Prescribing of drugs for use outside their licence in palliative care: survey of specialists in the United Kingdom
}

\author{
Hilary Pavis, Andrew Wilcock
}

Hayward House Macmillan Specialist Palliative Care Unit, Nottingham City Hospital NHS Trust, Nottingham NG5 1PB

Hilary Pavis specialist registrar in palliative medicine

continued over

BMJ 2001;323:484-5
A quarter of all prescriptions in palliative medicine are for licensed drugs that are used for unlicensed indications or that are given by an unlicensed route. Such prescriptions may affect two thirds of inpatients in specialist palliative care units. ${ }^{12}$ Doctors have been recommended to record in the patient's notes the reason for prescribing outside the licence; to explain, where possible, the position to the patient (and carers, if appropriate) in sufficient detail to allow informed consent to be given; and to inform other professionals involved in the care of the patient of such prescribing, so that misunderstandings are avoided. ${ }^{3}$ Given the widespread use of drugs outside their licence in palliative care, strict adherence to these recommendations

\begin{tabular}{|c|c|c|c|}
\hline $\begin{array}{l}\text { 1. Does your service operate a policy on providing information to } \\
\text { patients and their carers about the prescribing of } \\
\text { licensed drugs for unlicensed uses/routes? }\end{array}$ & \multicolumn{2}{|c|}{$\begin{array}{l}\text { Yes } \\
2(2)\end{array}$} & $\begin{array}{c}\text { No } \\
113(97)\end{array}$ \\
\hline \multicolumn{4}{|l|}{$\begin{array}{l}\text { If 'yes' please provide any details/documentation of any policy } \\
\text { your service is operating }\end{array}$} \\
\hline 2. Do you limit the prescribing of drugs in this way to consultants & \multicolumn{2}{|c|}{$20(17)$} & $93(79)$ \\
\hline 3. Do you obtain verbal consent from the patient/carers? & $\begin{array}{l}\text { Always } \\
5(4)\end{array}$ & $\begin{array}{c}\text { Sometimes } \\
62(53)\end{array}$ & $\begin{array}{l}\text { Never } \\
45(38)\end{array}$ \\
\hline 4. Do you obtain written informed consent from the patient/carers? & $0(0)$ & $4(3)$ & $109(93)$ \\
\hline $\begin{array}{l}\text { 5. Do you document in the notes when you are using drugs outside } \\
\text { of their licence and the reasons for this? }\end{array}$ & $6(5)$ & $48(41)$ & $58(50)$ \\
\hline 6. Do you inform other professionals when using such medication? & $7(3)$ & $80(68)$ & $25(21)$ \\
\hline $\begin{array}{l}\text { If you have answered 'always' to any of the above please provide } \\
\text { details/documentation of any policy your service is operating } \\
\text { If you have answered 'sometimes' to any of the above please } \\
\text { answer the following questions }\end{array}$ & & & \\
\hline $\begin{array}{l}\text { 7. How often have you obtained verbal or written informed consent } \\
\text { from patients/carers or documented in the notes the reasons for using } \\
\text { licensed drugs for unlicensed uses/routes in the past six months? }\end{array}$ & $\begin{array}{c}\text { No of ti } \\
0 \\
1-3 \\
4-6 \\
7-10 \\
>10\end{array}$ & $\begin{array}{l}1 \\
4 \\
1 \\
1\end{array}$ & $\begin{array}{c}16(20) \\
41(50) \\
14(17) \\
1(1) \\
10(12)\end{array}$ \\
\hline \multicolumn{4}{|l|}{ 8. Please list the particular drugs, their use and route of administration } \\
\hline $\begin{array}{l}\text { 9. Please add any comments that you may have about the obtaining } \\
\text { of informed consent from patients/carers and documenting the use of } \\
\text { licensed drugs for unlicensed purposes/routes in relation to your } \\
\text { palliative medicine practice }\end{array}$ & & & \\
\hline
\end{tabular}

Questionnaire on unlicensed use of drugs that was sent to palliative medicine specialists, with numbers (percentages) of responses $(n=117)$ to multiple choice questions may be impractical. In view of the implications of these recommendations for doctors in palliative medicine and other doctors they advise, a position statement endorsed by the specialty would be helpful. We undertook a survey of current practice to inform the debate.

\section{Participants, methods, and results}

All 182 palliative care services in the United Kingdom with a medical director or consultant were asked to complete anonymously a postal questionnaire in October 1999 (figure). Informed consent was defined thus: "Patients have been given the information they asked for or need about their treatment in a way they can understand so that whenever possible the patients have understood the nature, purpose and material risks of what is proposed and consent to it before you provide treatment."

One hundred and seventeen questionnaires (64\%) were returned. When unlicensed prescribing was limited to consultants, this was generally in the context of a consultant based service. No respondents always obtained written consent to unlicensed use, and only a minority $(<5 \%)$ always obtained verbal consent, documented unlicensed use in the patient's notes, or informed other professionals of it. The drugs for which these recommended practices were sometimes carried out were ketamine (58 reports), octreotide (19), ketorolac (15), midazolam (10), gabapentin (10), and amitriptylline (10). The only unlicensed drug use for which three of the services sometimes obtained written consent was gabapentin for neuropathic pain-an indication for which it became licensed in 2000 .

Invited comments covered three main themes. Firstly, respondents said that, given the prevalence of unlicensed use, it is impractical to obtain written consent routinely-and that discussion of unlicensed use could create unnecessary anxiety for the patient or carer. Secondly, some respondents sought consent only when prescribing drugs whose unlicensed use was not established in the specialty. Finally, other respondents made no distinction between licensed and unlicensed use and did not obtain verbal informed consent for use of any drug. 